\title{
A PRÁXIS PRODUTIVA NAS RELAÇÕES DE PRODUÇÃO-FORMAÇÃO DOS PESCADORES dA COLÔNIA Z-16 de CAMETÁ-PA
}

\author{
The productive praxis in the relations of production-training of the fishermen of \\ z-16 Colony in Cametá-PA
}

\author{
RODRIGUES, Adenil Alves ${ }^{1}$ \\ MARTINS, Egídio² \\ ARAUJO, Ronaldo Marcos de Lima ${ }^{3}$
}

\begin{abstract}
Resumo
O presente estudo é parte de resultado de tese de doutorado, defendido em 2017, sob o título: Pescadores Artesanais da Z-16: relações de produção-formação e práxis política. Faz-se aqui uma análise da práxis produtiva nas relações de produção-formação dos pescadores da Colônia Z-16 de Cametá-Pa, enquanto instrumento de contestação da realidade desses sujeitos. Por meio da aplicação de entrevistas semiestruturadas (MICHELAT, 1985), e com os dados analisados com base no materialismo histórico-dialético (MARX, 2008), sustenta-se que a práxis produtiva dos pescadores vem se apresentando enquanto mecanismo de não aceitação das negações produzidas pelo modo de produção vigente e, também, enquanto luta pela transformação da realidade. Conclui reconhecendo que a práxis produtiva se revela na ação constante dos pescadores e que as próprias limitações que hoje esses sujeitos sofrem em relação à construção de uma existência plena, bem como as relações próprias do mundo interiorano no qual estão inseridos, se transformam em mecanismos potencializados no sentido de avançar para além das negações e contradições cotidianamente enfrentadas.
\end{abstract}

Palavras-chave: Práxis produtiva. Produção-formação. Colônia de Pescadores Artesanais Z-16 de Cametá.

\section{ABstract}

This study is part of a result of the doctoral thesis defended in 2017 whose title was "Artisan Fishermen of Z-16 Colony: relations of production-training and political praxis. An analysis of the productive praxis in the relations of production-training of the fishermen of Z-16 Colony of Cametá-PA is carried out, once such praxis is a tool of contestation of the reality of those individuals. Through the application of semi-structured interviews (MICHELAT, 1985) in conjunction with data analyzed based on dialecticalhistorical materialism (MARX, 2008), it is held that the productive praxis of the fishermen has become a mechanism of disallowance of the denial produced by the current production method as well as a struggle for the transformation of the reality. It is concluded that the productive praxis is revealed in the constant actions of the fishermen and that their own limitations of today concerning the construction of a full existence as well as their own relations with the countryside environment they are in become strengthened mechanisms with a view to moving beyond the everyday denials and contradictions.

Keywords: Productive praxis. Production-training. Artisan Fishermen of Z-16 Colony of Cametá.

\footnotetext{
${ }^{1}$ Mestre em Educação (UFPA). Graduado em Letras-Habilitação em Língua Portuguesa (UFPA). Atualmente tutor Presencial das turmas de Letras (Habilitação-Língua Portuguesa) da Universidade Aberta do Brasil (UAB/UEPA) e Professor Colaborador no Campus Universitário do Tocantins (UFPA/Cametá). Membro do Grupo de Estudos e Pesquisas sobre Trabalho e Educação (GEPTE/UFPA). Email: adenil2007ufpaa@yahoo.com.br

${ }^{2}$ Doutor em Políticas Públicas Educacionais pelo Instituto da Ciência da Educação da Universidade Federal do Pará. Membro do Grupo de Estudos e Pesquisas sobre Trabalho e Educação-GEPTE/UFPA. Docente da UFPA-Campus Universitário do TocantinsCametá/Pará. E-mail: egidio@ufpa.br

3 Doutor em Educação pela UFMG. Professor do Curso de Pedagogia e do Programa de Pós-Graduação em Currículo e Gestão da Escola Básica da Universidade Federal do Pará. Coordenador do GEPTE - Grupo de Estudos e Pesquisas sobre Trabalho e Educação. E-mail: rlima@ufpa.br
}

Trabalho \&Educação | v.28 | n.2 | p.131-143 | maio-ago | 2019 


\section{INTRODUÇÃO}

O presente estudo é parte de resultado de tese de doutorado, defendido em 2017, sob o título: Pescadores Artesanais da Z-16: relações de produção-formação e práxis política. Objetiva analisar a práxis produtiva nas relações de produção-formação dos pescadores afiliados a Colônia Z-16, como contestação da realidade vigente. A presente análise parte do seguinte questionamento: como os pescadores da Z-16 produzem práxis produtiva no contexto de suas relações de produção-formação, capaz de servir como instrumento de contestação da realidade vigente, ao mesmo tempo, construindo alternativas de melhorias de condições de existência para esses sujeitos no contexto de sua realidade?

Os pescadores artesanais afiliados a Colônia4 Z-16 de Cametá5-PA, vivem as negações e contradições de uma realidade produto do modo de produção vigente que provoca e cultiva a desigualdade. São sujeitos que historicamente se posicionam contra a lógica do sistema do capital, por meio de lutas e práxis produtiva cotidiana, na perspectiva da transformação social.

A práxis produtiva dos pescadores da Z-16, é produto de suas relações de produçãoformação, construída nas interações sociais por meio do trabalho. São atividades que materializa pensar-agir enquanto transformação da realidade que permitem esses pescadores contestar e, portanto, se contrapor ao modo de produção vigente que interdita a possibilidade de viver o mundo da liberdade, impondo, em contrapartida, o aprisionamento no mundo das necessidades.

Entende-se por produção-formação a relação dialética do homem com a natureza intermediada pelo trabalho, para a produção da vida material humana. Esse ser social, é produto de um processo histórico, dotado de capacidade para adaptar a natureza, a sua realidade, ao mesmo tempo transformando a si mesmo. "Aquilo que os indivíduos são depende, portanto, das condições materiais da sua produção" MARX e ENGELS, 2009 , p. 25). Assim, o modo como os homens produzem, determina as condições da vida social, da sua formação como ser humano. "[...] o modo de produção da vida material condiciona o desenvolvimento da vida social, política e intelectual em geral" (MARX, 2016, p. 5).

Assim, problematizou-se a práxis produtiva dos pescadores nas relações de produçãoformação enquanto mecanismo de contestação da realidade, a partir das atividades

\footnotetext{
${ }^{4}$ Embora o termo Colônia possa suscitar a imagem de um coletivo de pescadores vivendo da pesca à margem de um rio, a Colônia de Pescadores Artesanais Z-16 se constitui na entidade representativa de classe desses sujeitos, reunindo 15.000 associados de diferentes comunidades do município cametaense. Sua fundação data de 1923. Segundo Moraes (2002), a letra Z refere-se à Zona de Pesca e o número 16 indica ser esta Colônia a décima sexta criada no Estado do Pará. Para Costa (2006, p. 153), a Colônia Z-16 se constitui em organização política importante para o alcance dos interesses dos trabalhadores na região em que se encontra o município de Cametá: "Diante das duras condições sociais e econômicas, o campesinato regional vem se organizando e a força com a qual os trabalhadores têm conseguido intervir na vida política da região é fruto de um razoável capital social acumulado na construção histórica de fortes instrumentos de luta e enfrentamento com setores oligárquicos tradicionais. Organismos de classe como a Colônia de Pescadores Z-16, fundada ainda na década de 1920 e o STR que data dos anos 1960, bem como uma rede de associações, no decorrer desses anos vêm impulsionando mudanças qualitativas no que se refere à organização de sua base social, conquista de créditos e financiamento de projetos agrícolas e ambientais, bem como vitórias eleitorais sobre antigas e tradicionais oligarquias" (RODRIGUES, 2012, p. 31).

${ }^{5} \mathrm{O}$ município de Cametá, segundo o Instituto Brasileiro de Geografia e Estatística - IBGE (2010), pertence à mesorregião do nordeste paraense e à microrregião Cametá, apresentando uma área correspondente a $3.122 \mathrm{~km}^{2}$. Ainda segundo aquele instituto, o município apresenta uma população de 120.896 habitantes, dos quais 52.838 encontram-se na zona urbana e 68.058 na zona rural. Trata-se de um município com contingente rural maior do que o urbano (ldem).
} 
desses sujeitos como trabalhadores comprometidos com a melhoria de condições de sua existência. Para coletar os dados junto aos entrevistados utilizou-se as entrevistas semiestruturadas (MICHELAT, 1985), de modo que essa contribui para extrair as informações dos pesquisados num contexto que se aproxima das relações naturais de vivências dos sujeitos.

Para analisar os dados apoiou-se no materialismo histórico-dialético ${ }^{6}$ (MARX, 2008), por compreender que esse possibilita leitura contextualizada, numa relação de contradição. Como resultado, sustenta que a práxis produtiva desses sujeitos vem se apresentando enquanto mecanismo de resistência às negações produzidas pelo modo de produção vigente e, também, enquanto estratégia de transformação da realidade, em prol dos benefícios dos pescadores.

O presente texto está dividido em três seções: na primeira busca-se discutir o "Trabalho humano e a constituição da práxis produtiva", destacando que é por meio do trabalho que a práxis produtiva se materializa. Na segunda seção, sob o título "As relações de produção-formação", analisa que não é a dimensão abstrata que habita o pensamento humano que resulta nas relações de produção-formação vivenciada pelos pescadores, mas as relações materiais com as quais cotidianamente estabelece intercâmbios para garantir a subsistência. Na terceira e última seção, sob o título "A práxis produtivas dos pescadores da Colônia Z-16 de Cametá-PA", demonstra a partir dos dados coletados, como a práxis produtiva nas relações de produção-formação desses sujeitos configurase como mediação de contestação da realidade. Por fim, expomos as considerações finais.

\title{
2. TRABalho humano e a CONSTITUIÇÃo dA PRÁxis PRODUTIVA
}

Para Marx (2013), o trabalho é a categoria fundante da relação entre o homem com a natureza. Nesse sentido, o homem pelo trabalho executa, medeia e, no movimento permanente busca atendimento de suas necessidades, produz condições básicas de sua existência. Nos escritos do autor citado, "O trabalho é, antes de tudo, um processo entre o homem e a natureza, processo este em que o homem, por sua própria ação, medeia, regula e controla seu metabolismo com a natureza" (p. 255).

O homem sem trabalho não viveria, de modo que a transformação que faz na natureza exterior produz mudanças na sua própria natureza, num movimento dialético. A relação que o homem estabelece com a natureza não é algo isolado, mas construído a partir da complexa interação que estabelece entre seu ser e o mundo material, afim de promover a realização de um determinado fim.

\begin{abstract}
Além do esforço dos órgãos que trabalham, a atividade laboral exige a vontade orientada a um fim, que se manifesta como atenção do trabalhador durante a realização de sua tarefa, e isso tanto mais quanto menos esse trabalho, pelo seu próprio conteúdo e pelo modo de sua execução, atrai o trabalhador, portanto, quanto menos este último usufrui dele como jogo de suas próprias forças físicas e mentais (MARX, 2013, p. 256).
\end{abstract}

A antecipação da ação no campo teleológico diferencia o homem dos animais, de modo que essa antecipação não é simples passagem do campo ideal para o real, mas

\footnotetext{
${ }^{6}$ O materialismo dialético, [...] é ao mesmo tempo uma filosofia e um método de se fazer ciência. Por ser materialismo e por ser dialético não poderia ter outra lógica que não fosse a própria lógica dialética, uma lógica voltada para o conteúdo do conhecimento, para o concreto (SALOMON, 2000, p. 198)
} 
uma atividade específica do homem, que determina sua ação, produz objetividade, transforma a natureza e a sua realidade para dar conta de suprir suas necessidades. Conforme Marx (2013, p. 258) o "[...] processo de trabalho opera uma transformação do objeto do trabalho segundo uma finalidade concebida desde o início [...]. Seu produto é um valor de uso, um material natural adaptado às necessidades humanas por meio da modificação da sua forma".

Assim, o trabalho é a categoria central produtora da existência humana, de modo que no processo do trabalho um conjunto de elementos vai se articulando, produzindo mudança na natureza humana. Marx (2013) também chama atenção para o fato de que no resultado de um produto final, os meios e os objetos do trabalho são também meios de produção, dessa forma o trabalho torna-se produtivo.

Quando um valor de uso resulta do processo de trabalho como produto, nele estão incorporados, como meios de produção, outros valores de uso, produtos de processos anteriores. O mesmo valor de uso que é produto desse trabalho constitui o meio de produção de um trabalho ulterior, de modo que os produtos são não apenas resultado, mas também condição do processo de trabalho (MARX, 2013, p. 258-259).

O trabalho produz o próprio homem, de modo que sua intervenção na natureza para produzir bens necessário à sua subsistência requer o envolvimento do homem em sua totalidade, nesse processo as transformações tanto da natureza externa como da natureza humana são dialéticas, de modo que um interfere no outro, e a mudança somente é possível nesses dois elementos homem/natureza.

Nessa relação o homem produz um mundo adaptado a sua realidade, para suprir suas necessidades. Conforme Vázquez (2011, p. 228) "[...] graças ao trabalho, o homem vence a resistência das matérias e forças naturais e cria um mundo de objetos úteis que satisfazem determinadas necessidades". É nesse mundo construído, adaptado ás estruturas humanas, no sentido de objetividade e subjetividade, direcionado para alcançar determinado fim que Váquez (2011) chama de práxis produtiva.

A práxis produtiva é, assim, a práxis fundamental porque nela o homem não só produz um mundo humano ou humanizado, no sentido de um mundo de objetos que satisfazem necessidades humanas e que só podem ser produzidos na medida em que se plasmam neles fins ou projetos humanos, como também no sentido de que na práxis produtiva 0 homem se produz forma ou transforma a si mesmo (VÁZQUEZ, 2011, p. 230).

Assim, a práxis produtiva possibilita a formação do próprio homem, uma formação que ultrapassa a necessidade biológica, mas amplia-se para relações de outras dimensões, como socioeconômica e política. Nessas dimensões o homem se objetiva, constrói um mundo de possibilidade, de relações de produção. Conforme Kosik (2002, p. 222) "[...] na práxis do homem advém algo essencial, que contém em si mesmo a própria verdade, não é mero símbolo de qualquer outra coisa, mas possui uma importância ontológica". É pela práxis que o homem conhece a si mesmo e o mundo que o rodeia, numa relação indissociável de teoria e prática. De acordo com Kosik (2002, p. 22) "[...] a práxis do homem não é atividade prática contraposta à teoria; é determinação da existência humana como elaboração da realidade"

A práxis produtiva possibilita a constituição humana, num conjunto de relações dialéticas ao longo do processo histórico. É pela práxis que se pode compreender a distinção entre o humano e os demais seres vivos. É na prática que se materializa a 
objetivação e a liberdade humana, como fica explicito na segunda tese de Marx sobre Feuerbach.

\begin{abstract}
A questão de saber se ao pensamento humano cabe alguma verdade objetiva [gegensandliche Wahrbeif] não é uma questão da teoria, mas uma questão prática. Na prática, tem o homem de provar a verdade, isto é, a realidade e o poder, a natureza interior [Diesseitigkeit] de seu pensamento. A disputa acerca da realidade ou não realidade de um pensamento que se isola da prática é uma questão escolástica (MARX e ENGELS, 2009, p. 123-124, grifos do autor).
\end{abstract}

É na relação dialética entre teoria e prática, ou melhor, na práxis que o homem constrói objetividade e subjetividade, um ser diferente de outros, porque pensa, sente, planeja e desenvolve a capacidade de transformação da sua existência, relacionado com o passado, presente e futuro. Conforme Kosik (2002, p. 225) "[...] a práxis como criação da realidade humana é ao mesmo tempo o processo no qual se revelaram em sua essência, o universo e a realidade". Nessa relação existencial o homem promove sua liberdade, uma criação da realidade em diversas dimensões das condições humanas. Ou seja, no processo de relação de produção-formação o homem constrói práxis produtiva capaz de dar contar de sua existência.

\title{
3.AS RELAÇÕES DE PRODUÇÃO-FORMAÇÃO INERENTE A EXISTÊNCIA HUMANA
}

Na obra "Ideologia Alemã" Marx e Engels (2009) explicitam que o homem ao produzir suas condições de vida, forma-se como sujeito cognoscente. Assim, a matéria, as relações de produção, antecedem o conhecimento, a cultura humana. "Ao produzir os meios de subsistências, o homem produz indiretamente a sua própria vida material" ( $p$. 24). O mundo material existe independente do conhecimento, esse por sua vez é produto das relações humanas num conjunto inter-relacionado com a matéria. "Aquilo que os indivíduos são depende, portanto, das condições materiais da sua produção" (idem).

A matéria é a base fundamental da existência humana, a construção do pensamento somente é possível por intermédio das relações materiais, das condições necessárias para proporcionar a própria vida. Em outras expressões, para o ser humano se manter vivo, faz-se necessário à produção de alimentos, abrigos e vestimentas. São os primeiros elementos fundamentais da perpetuação da espécie humana. Para Marx e Engels (2009, p. 34), esses elementos são básicos para a construção histórica da liberdade, isso nos leva a concordar que "[...] de modo algum se podem libertar os homens enquanto estes não estiverem em condições de adquirir comida e bebida, habitação e vestuário na qualidade e na quantidade perfeitas".

Ao mesmo tempo em que o homem produz os elementos necessários de sua existência, forma-se como sujeito cognoscente, ou melhor, produz cultura, conhecimento e saber da sua existência. A produção-formação é inerente à vida humana, de modo que ao produzir, o homem se forma como sujeito objetivo e subjetivo, como produto de suas relações materiais. $O$ ato de conhecer, de compreender, de construir está inter-relacionado com as atividades humanas, ou melhor, com o trabalho. É esse (o trabalho), a categoria central da construção social, ao mesmo tempo em que o homem trabalha, para dar conta de garantir sua subsistência, forma-se como sujeito consciente de sua realidade. 
A produção das ideias, das representações, da consciência está em princípio diretamente entrelaçada com a atividade material e o intercâmbio material dos homens, linguagem da vida real. O representar, o pensar o intercâmbio espiritual dos homens aparece aqui ainda como direta exsudação do seu comportamento material (MARX e ENGELS, 2009, p. 31).

$\mathrm{Na}$ concepção materialista da história, o processo da produção-formação é compreendido como unidade de modo que ao mesmo tempo em que o homem modifica a natureza exterior para suprir suas necessidades básicas, modifica também sua própria natureza, adequando seus organismos no processo da produção. Um movimento dialético centrado na categoria trabalho.

O homem é produto das relações de produção construído ao longo do processo histórico, uma relação sempre necessária e determinada. São relações de produção inter-relacionadas com as forças produtivas da sociedade. Essa por sua vez é a base material da constituição social, como afirma Marx (2016, p. 5), "[...] na produção social de sua existência, os homens estabelecem relações determinadas, necessárias independente de sua vontade, relações de produção que correspondem a um determinado grau de desenvolvimento das forças produtivas materiais".

As forças produtivas e as relações de produção são bases que sustentam toda a estrutura e a superestrutura da sociedade. Assim, "[...] o conjunto destas relações de produção constitui a estrutura econômica da sociedade, a base concreta sobre a qual se eleva uma superestrutura jurídica e política e à qual correspondem determinadas formas de consciência social" (MARX, 2016, p. 5). Mas antes de chegar nesse grau de desenvolvimento da sociedade, o homem se apropriou da natureza por meio do trabalho.

Essa apropriação possibilitou a esse ser construir relações determinadas com a natureza externa e com sua própria natureza, ao mesmo tempo se transformando num ser diferente de outros seres, porque antecipa mentalmente sua atividade antes de sua materialização. Dessa forma, as forças produtivas estão entrelaçadas com as relações do homem com a natureza e as relações de produção se efetivam sob o domínio do homem sobre o próprio homem. Pela limitação de nossa análise, daremos atenção a essa última, para em seguida relacionar com a práxis produtiva dos pescadores da Z16 , objeto do presente artigo.

As relações de produção são materializadas em cada período histórico da sociedade e dependem do desenvolvimento das forças produtivas. De acordo com Marx e Engels (2009, p. 25), "[...] as relações de diferentes nações entre si dependem do grau em que cada uma delas desenvolveu as suas forças produtivas, a divisão do trabalho e 0 intercâmbio interno". Compreender as relações de produção possibilita analisar a estrutura dialética da sociedade.

Santos (1984) destaca três elementos que compõem as relações de produção. O primeiro elemento que o autor destaca são as relações de trabalho. Para Marx e Engels (2009) as relações de trabalho estão articuladas diretamente com a divisão do trabalho, esse por sua vez provoca o processo de alteração no conjunto da estrutura social. "A divisão do trabalho no interior de uma nação começa por provocar a separação do trabalho industrial e comercial do trabalho agrícola e, com ela, a separação da cidade e campo e a oposição dos interesses de ambos" (p. 26). O desenvolvimento das forças de trabalho altera também as relações dos indivíduos, assim como seus instrumentos e suas relações de trabalho. 
Ainda segundo Marx e Engels (2009) a primeira relação de trabalho é a organização tribal, nessa relação não há desenvolvimento nas relações de produção, visto que as tribos sobreviviam da caça e pesca. Aqui a divisão do trabalho é um prolongamento da família, articulado entre os próprios membros, que compõem a hierarquia social. Para Santos (1984) a relação de trabalho com caráter de exploração, surgiu com o modo de produção escravista, que após disputa por território a tribo vencedora utilizava-se da mão-de-obra da tribo derrotada.

\begin{abstract}
A primeira forma de relação trabalhista, baseada na exploração do trabalho alheio, é constituída pela escravidão, inicialmente exercida pela submissão de tribos derrotadas por tribos vencedoras e que, posteriormente, já na Grécia Antiga, dá origem a um comércio organizado, que se apoia em expedições explicitamente dedicadas à aquisição - por compra ou pilhagem - de grandes grupos de escravos (SANTOS, 1984, p. 58).
\end{abstract}

Os escravos derrotados exerciam diversas funções na divisão social do trabalho, como por exemplo, trabalhos nas minas, nas atividades agrárias, auxiliares de artesãos, serviços domésticos, artísticos entre outros. Para Marx e Engels (2009, p. 27): "[...] com o desenvolvimento da sociedade privada surge aqui, pela primeira vez, as mesmas relações que voltamos a encontrar na propriedade privada moderna, só que nesta em maior escala". Para Santos (1984) a submissão do trabalho escravo em diversas funções, compondo a divisão social do trabalho, demonstra a decadência do modo de produção escravista, assim como a falência da estrutura social do Império Romano.

Com a decadência do modo de produção escravista, surge uma estrutura de produção fixa e constante, o feudalismo. Assim destaca Marx e Engels (2009, p. 29): "[...] a propriedade principal consistia assim, durante a época feudal, por um lado, na propriedade fundiária e no trabalho do servo a ela preso, e, por outro, no trabalho próprio com um pequeno capital a dominar o trabalho dos oficiais". Uma relação de produção pautada na pequena agricultura rudimentar e na indústria artesanal. A estrutura social do feudalismo estava marcada por duas classes distintas, o servo e o senhor feudal. A primeira vinculava diretamente a produção, a segunda classe, os nobres detinham o poder sobre feudo e os servos. Essa estrutura supera a forma de produção escravista.

Com a decadência do feudalismo, inaugura-se uma relação de trabalho pautado na propriedade privada, sustentada pela compra da mão-de-obra no processo da produção, materializado por um salário pago mensalmente. $O$ trabalhador nessa relação de produção é considerado livre, vinculado aos donos dos meios de produção. Para Marx $(2008$, p.) nesse modo de produção a indústria ganha destaque, assim como o comércio, a navegação e circulação de mercadorias em todo o mundo.

A grande indústria criou o mercado mundial, preparado pela descoberta da América. $\mathrm{O}$ mercado mundial promoveu um desenvolvimento incomensurável do comércio, da navegação e das comunicações. Esse desenvolvimento, por sua vez, voltou a impulsionar a expansão da indústria. $E$ na mesma medida em que a indústria, comércio, navegação e estradas de ferro se expandiram, desenvolvia-se a burguesia, os capitais se multiplicavam e, com isso, todas as classes oriundas da Idade Média passavam a um segundo plano (MARX, 2008, p. 10-11).

Assim, a nova fase de produção não somente inaugura uma nova relação de trabalho, promove também as lutas de classe, a burguesia, classe que concentra os meios de produção, e a classe dos proletariados, que detém somente a força de trabalho. Conforme Marx (2008, p. 9): "[...] a moderna burguesia, que surgiu do declínio da 
sociedade feudal, não aboliu as contradições de classe. Ela apenas colocou novas classes, novas condições de opressão e novas formas de luta no lugar das antigas". Assim, o modo de produzir do capitalismo se efetiva na compra da mão-de obra, por meio de um salário, nesse processo se materializa a relação de exploração do homem pelo próprio homem.

O segundo elemento que compõem as relações de produção, Santos (1984) destaca como sendo as formas de propriedade. Essa por sua vez representa um conjunto de relações de trabalho, envolvendo a divisão, as condições, os instrumentos, as distribuições e entre outros no campo do trabalho.

\begin{abstract}
A divisão social do trabalho não é uma simples divisão de tarefas, mas a manifestação de algo fundamental na existência histórica: a existência de diferentes formas da propriedade, isto é, a divisão entre as condições e instrumentos ou meios do trabalho e o próprio trabalho, incidindo, por sua vez, na desigual distribuição do produto do trabalho. Numa palavra: a divisão social do trabalho engendra e é engendrada pela desigualdade social ou pela forma da propriedade (CHAUÍ, 1980, p. 24).
\end{abstract}

A primeira forma de propriedade é a tribal. Uma estrutura social ainda rudimentar, mas já se podia perceber as relações de produção, circulando no contexto da sociedade. Conforme Chauí (1980, p. 24) "A propriedade começa como propriedade tribal e a estrutura social é a de uma família ampliada e hierarquizada por tarefas, funções, poderes e consumo". Essas relações foram possibilitadas pela fixação da tibo ao solo, construindo intercâmbio trabalhista com outras tribos.

A segunda forma de propriedade é a comunal, uma estrutura de organização social dividida entre senhores e escravos, desenvolvida na Grécia e Roma. Uma estrutura que não somente dividi as classes, mas também as relações de produção, entre campo e cidade. Essa divisão para Chauí (1984, p.24): "[...] leva os senhores a viverem nas cidades e a partir daí se estabelece a separação entre a cidade e o campo, de onde resultarão lutas sociais e políticas". Marx e Engels (2009) chamam atenção que a maior separação do trabalho material e espiritual é a separação entre campo e cidade.

A terceira forma de propriedade é a feudal, sustentada pelos trabalhos do servo, submisso ao proprietário da terra. Além dos servos, existiam os artesãos livres que viviam nos burgos da cidade. Conforme Chauí (1980, p. 24): "[...] a estrutura da sociedade cria os proprietários como nobreza feudal e como oficiais livres dos burgos, e os trabalhadores como servos da terra enfeudada e como aprendizes nas corporações dos burgos". Uma relação de trabalho pautado na fixação da terra e no controle dos trabalhadores. Vale mencionar que não era uma relação amigável, mas um modo de produção em constantes conflitos. Como frisa Marx e Engels (2009, p. 79): "[...] os grandes levantes da Idade Média partiram todos do campo, mas ficaram igualmente sem qualquer êxito devido à dispersão dos camponeses e à crueza que dela decorre". As mudanças nas relações de trabalho e de propriedade dos feudos impulsionaram o modelo de propriedade vigente.

Chauí (1980) destaca que a forma de propriedade do capitalismo alcança seu ápice, de modo que há uma clara divisão nas relações de trabalho, de um lado os proprietários dos meios de produção, do outro, os trabalhadores assalariados, ganhando por meio de sua força de trabalho. Conforme Santos (1984, p. 62) 
[...] para o trabalhador, a generalização da propriedade privada significou, também, o direito de vender livremente sua força de trabalho a qualquer patrão interessado ou de converterse ele mesmo em patrão, ao fazer-se proprietário dos meios de produção.

Nessa relação de produção o trabalhador é livre, pois é proprietário de sua força de trabalho, pode vender no mercado da forma que achar mais apropriado.

O terceiro elemento conforme Santos (1984) que compõem as relações de produção, são as relações de distribuição e de troca. Para Marx (2016) a distribuição

[...] é um produto da produção, não só no que diz respeito ao objeto, apenas podendo ser distribuído o resultado da produção, mas também no que diz respeito à forma, determinando o modo preciso de participação na produção às formas particulares de distribuição, isto é, determinando de que forma o produtor participará na distribuição (MARX, 2016, p. 241).

A distribuição é um elemento fundamental na produção, de modo que amplia e apresenta um novo caráter a produção, num movimento dialético. Antes da distribuição dos produtos, há uma distribuição dos instrumentos e dos indivíduos na sociedade, pelos diversos ramos da produção. Acompanhado da distribuição, a troca é um momento fundamental no processo da produção, em outras palavras, é parte da produção. Conforme Marx (2016, p. 245): "[...] em primeiro lugar, é evidente que a troca de atividades e de capacidade que tem lugar na própria produção faz diretamente parte desta, constituindo um dos seus elementos essenciais".

Assim, a distribuição e a troca não são idênticas, mas compõem um contexto articulado no processo da produção. Esse por sua vez sofre novas estruturas provocadas pelas distribuições e troca das mercadorias para se adaptar ao desenvolvimento das forças produtivas. Para Santos (1984, p. 67): "[...] as mudanças das forças produtivas, pressupostas nos diferentes modos e produção, alteram não somente suas estruturas, mas também o resultado possível da luta de classes que se trava no seu seio".

As análises em torno das relações de produção requerem a compressão do desenvolvimento de um tipo de sociedade em cada período histórico, mas evidenciando que a produção está inter-relacionada com a formação. Assim, fica explicito que a estrutura material de uma determinada sociedade, impulsiona diretamente a forma de pensar e agir dos homens dessa sociedade, em outras palavras, as relações de produção-formação são indissociáveis na condição da existência humana.

\section{A PRÁXIS PROdUTIVA E AS RELAÇÕES DE PRODUÇÃO-FORMAÇÃo dOS PESCADORES dA ColônIA Z-16 de CAMETÁ-PA}

A Colônia de Pescadores Z-16, lócus da presente pesquisa, é um movimento social de pescadores artesanais que historicamente vêm construindo espaços produtivos a partir de suas atividades com a pesca no município de Cametá no Estado do Pará. É uma entidade que segundo Rodrigues (2012) é composta por mais de 15 mil afiliados, organizados em mais de 80 coordenações em diversas comunidades, objetivando proporcionar melhorias de condições de vida aos pesadores agregados na entidade.

As relações de produção-formação dos pescadores da Z-16 é produto de suas atividades cotidianas que se dão ao longo do processo histórico articulado com aspectos socioeconômico, político e formativo desses sujeitos. São ações que se 
integram a práxis produtiva desses pescadores para além da atividade técnica da pesca, em prol de suas organizações como representatividade de uma fração de classe. São organizações que se contrapõem as ideologias do capital, porque não requer produção em larga escala, não visa grandes lucros, não envolve relação de compra e venda. É uma práxis voltada para dar conta de suprir as necessidades básicas dos pescadores numa relação de contradição. Essa contradição, por sua vez, refere-se

[...] à reconfiguração material da existência dos pescadores impossibilitando, em termos de produção-formação, que as gerações mais novas tenham acesso a saberes produzidos pelas gerações que lhes antecederam. Assim, a produção-formação do sujeito pescador enquanto coletivo vai sofrendo um processo de esvaziamento de elementos que 0 constroem enquanto pescador, partícipe de coletivo de sujeitos que se identificam por ações similares no campo do trabalho (RODRIGUES, 2012, p. 222).

Essa identificação dos pescadores da qual nos fala Rodrigues (2012) se refere às atividades desenvolvidas por esses sujeitos no contexto de seus trabalhos. Uma identidade construída num conjunto articulado em torno da pesca. Ou melhor, a pesca, como atividade técnica, por si só não representa a identidade dos pescadores, de modo que são trabalhadores vinculados a uma entidade, a Z-16, essa por sua vez reúne um coletivo de pescadores em torno de uma práxis produtiva. Isso posto,

Expomos que a construção de conhecimentos relacionados ao exercício do trabalho dos pescadores possibilita a compreensão do processo histórico de formação identitária de sujeitos que desenvolvem um tipo especial de ofício em oposição a ofícios desempenhados por contingentes outros de trabalhadores, o que lhes permite perceberem-se como semelhantes a partir do que fazem (RODRIGUES, 2012, p. 139).

Para Vázquez (2011, p. 228) a práxis produtiva é uma relação material do homem com a natureza, no sentido de suprir suas necessidades básicas, mas ao mesmo tempo transformando a natureza externa e a mudança teleológica do próprio homem. "[...] Entre as formas fundamentais da práxis temos a atividade prática produtiva, ou relação material e transformadora que o homem estabelece - mediante seu trabalho - com a natureza" (Idem). A organização produtiva dos pescadores da Z-16 é um movimento dialético que se efetiva no contexto de seu trabalho, tendo a pesca como referência para constituição de sua identidade, como fração de classe.

Para ser pescador artesanal faz-se necessário construir certos elementos básicos que compõem essa profissão, como por exemplo, a compreensão do movimento dos rios, fabricação e utilização dos instrumentos de pesca, tipos de pescados, entre outros. São condições essenciais que compõem a identidade do pescador, como destaca um de nossos entrevistados, aqui identificado como informante (3): "[...] acho que pescador que é pescador artesanal, deveria saber fazer seus instrumentos de pesca, como por exemplo, se você falasse comigo para fazer um matapi ${ }^{7}$, eu faria esse instrumento para o senhor".

Para o pescador da Z-16 dar conta de suprir suas necessidades construíram ao longo do processo histórico de sua existência, certos domínios sobre a natureza do seu entorno, o rio, o pescado entre outros. Uma profissão que requer relações não somente com a natureza externa, mas também com outros homens, ou melhor, com seus

\footnotetext{
${ }^{7}$ Instrumento de pesca artesanal, fabricado de tala, tecido com uma espécie de corda chamado cipó, ou náilon direcionado para a captura o camarão.
} 
pares. Nessa relação vão construindo experiência em diversos campos do saber, como por exemplo, da produção, da organização como coletivo de pescadores, são posturas que se articula com o posicionamento de Vásquez (2011, p. 228), quando afirma:

O homem vence a resistência das matérias e forças naturais e cria um mundo de objetos úteis que satisfazem determinadas necessidades. Mas, como o homem é um ser social, esse processo só se realiza em determinadas condições sociais, isto é, no marco de certas relações que os homens contraem como agentes da produção nesse processo e (sic) que Marx chama apropriadamente de relações de produção.

A práxis produtiva dos pescadores aqui analisados se materializa no movimento das relações de produção, compreendida essa como um conjunto de práticas construídas nas relações socioeconômicas, políticas e formativas. Como por exemplo, as experiências de trabalhar com diversas tecnologias de pesca, suas tradições religiosas, seus costumes, suas organizações políticas em torno de uma entidade como coletivo de pescadores. Nesse movimento os pescadores vão construindo no contexto de sua realidade concepção de sociedade, de mundo e de homem.

[...] o processo da pesca como elemento de identidade desse trabalhador implica um conhecimento sobre a totalidade do ofício realizado. O pescador, nesse sentido, não é o sujeito que domina parcialmente as ações de seu trabalho, como em linhas de montagem fordistas, mas aquele que demonstra conhecimentos sobre a natureza e sobre as tecnologias por ele criadas no interior de suas experiências de pesca e de suas necessidades laborativas, desenvolvendo uma práxis produtiva [...] (RODRIGUES, 2012, p. 142, grifos nossos).

O domínio da profissão de pescador inicia desde a infância, no seio ainda da família, uma aprendizagem herdada de geração para geração. Quando ainda criança o pescador acompanha seus familiares no desenvolvimento da atividade, realizando pequenas ações como coordenar a canoa, ajudar na captura dos peixes das redes e outros instrumentos, com essas ações os pescadores vão se apropriando das atividades da pesca, como frisa o Informante (4).

Eu acho que foi dos quinze anos já ia com o meu pai pilotar, remar, jogar rede, de lá não teve mais pai, da pesca eu sei de tudo, sei fazer malhadeira, matapi, tarrafa, um material de pesca que eu não sei fazer, se pedirem para mim fazer, é a rede de lanciar camarão, ela é difícil para gente fazer duas cabeças, mas que outros matarias de pesca, sei fazer, pari, por exemplo, para camboar na beira do rio, tudo isso a gente faz (PESCADOR, 4).

Os pescadores constroem sua práxis produtiva no cotidiano de sua realidade, uma misturara de trabalho, costume e tradições, que compõem as relações de produção. Nesse processo, acumula um conjunto de saberes necessários para dar contar de situar no contexto de sua existência, um processo dialético que vai se dando com a natureza, consigo mesmo e com seus pares.

O pescador é, então, o sujeito que, por meio de sua práxis produtiva, conhece o processo da pesca, implicando conhecimentos sobre marés, tipos de peixes e também sobre métodos e técnicas de pesca; possui seus instrumentos de pesca e sabe utilizá-los, como rede, caniço, malhadeira, o que demonstra um conhecimento especializado sobre o ofício que desenvolve. $O$ pescador é desse modo, um sujeito que adquire conhecimentos no cotidiano de sua prática profissional (RODRIGUES, 2012, p. 143).

Esse conhecimento do pescador, sobre o cotidiano de sua realidade, relatado por Rodrigues, se articula com os escritos de Marx e Engels (2009, p.123-24) na oitava 
tese sobre Feuerbach quando chama atenção para a construção humana a partir das relações materiais, deixam evidente que somente na prática o homem se objetiva, constroem relações de produção, materializada na práxis produtiva. "A vida social é essencialmente prática. Todos os mistérios que induzem a teoria ao misticismo encontram sua solução racional na prática humana e na compreensão dessa prática".

Assim, os pescadores da Z-16, ao produzirem instrumentos de pesca, demonstram segurança ao dominarem também de sua profissão, elementos fundamentais para garantir sua existência, dessa forma, vão se construindo como sujeitos da práxis produtiva, homens e mulheres que não somente dominam a natureza externa, mas transforma também sua própria natureza, elevando seus conhecimentos em diversos campos do saber, como socioeconômico, político e formativo.

\section{CONSIDERAÇões FinaIS}

As reflexões feitas nos permitiram inferir que a práxis produtiva nas relações de produção-formação dos pescadores da Colônia Z-16 de Cametá-Pa são resultantes do processo dialético de trabalho que os pescadores cotidianamente estabelecem com o meio social em que estão inseridos. Assim, no movimento interacional que vão estabelecendo com a natureza, com os apetrechos de pesca, com seus pares num momento históricos, os pescadores vão criando mecanismo, de organização, produção-formação no contexto da Colônia de Pescadores Artesanais Z-16 de Cametá-Pa, para que assim possam não só ter condições de enfrentar as contradições do modo de produção vigente, mas também para avançar rumo a uma realidade mais justa, possibilitando a construção de melhores alternativas em prol de seus benefícios.

Assim, esses sujeitos contestam a realidade vigente a partir da práxis produtiva, produto não da passividade diante das negações que sofrem, mas de posicionamento político contra hegemônica aos efeitos negativos de uma realidade que lhes obnubila a possibilidade de terem uma vida plena e humanamente construída.

A práxis produtiva nessa perspectiva se revela ação constante dos pescadores; e as próprias limitações que hoje sofrem em relação à construção de uma existência plena, bem como as relações próprias do mundo interiorano no qual estão inseridos se transforam em mecanismos potencializados para além das negações e contradições cotidianamente enfrentadas.

É nesse sentido que a práxis produtiva vem se mostrando um fenômeno presente nas ações e lutas dos pescadores, uma práxis que pela própria lógica do modo de produção em vigor, vem se mostrando necessária nas ações dos pescadores não só no sentido de lhes orientar a compreensão da realidade para além do dado imediato, mas também e principalmente, no sentido de lutar pela transformação do que fragiliza e os reduzem a simples mão-de-obra necessária para o funcionamento das engrenagens do sistema.

\section{REFERÊNCIAS}

CHAUÍ, Marilena. O que é ideologia? São Paulo: Brasiliense, 1980.

KOSIK, Karel. Dialética do concreto. Rio de Janeiro: Paz e Terra, 2002.

MARX, Karl; ENGELS Friedrich. A Ideologia Alemã. 1ํed. São Paulo: Expressão popular, 2009. 
MARX, Karl. O Capital: crítica da economia política. São Paulo: Boitempo, 2013.

MARX, Karl.O Capital: crítica da economia política. Rio de Janeiro: Civilização Brasileira, 2008. V.1.

MARX, Karl. Manifesto do Partido Comunista. 1를. ed. São Paulo: Expressão Popular, 2008.

MARX, Karl. Contribuição á crítica da economia política. Tradução Maria Helena Barreiro Alves; revisão da tradução Carlos Roberto F. Nogueiro.- 5ํe ed. - São Paulo: Editora WMF Martins Fontes, 2016.

RODRIGUES, Doriedson do Socorro. Saberes sociais e luta de classe: um estudo a partir da Colônia de Pescadores Artesanais Z-16-Cametá/Pará. 2012. 337 f. Tese (Doutorado) -Universidade Federal do Pará, Instituto de Ciências da Educação, Programa de Pós-Graduação em educação, Belém, 2012.

SANTOS, Theotonio dos. Forças produtivas e relações de produção ensaio introdutório. Tradução de Hugo Pedro Bofff. Petrópolis: Vozes, 1984.

SALOMON, Délcio Vieira. A maravilhosa incerteza: ensaio de metodologia dialética sobre problematização no processo do pensar, pesquisar e criar.São Paulo: Martins Fonte, 2000.

VÁZQUEZ, Adolfo Sánchez. Filosofia da Práxis. $2^{2}$ ed.- Buenos Aires: Consejo Latinoamericano de Ciências Sociais-Clacso: São Paulo: Expressão Popular, 2011.

Data da submissão: 30/04/2018

Data da aprovação: 08/06/2019 